\title{
Primary-secondary de-coupled ground source heat pump systems coefficient of performance optimization through entering water temperature control
}

Justin Marmaras ${ }^{\mathrm{a}}{ }^{1}$, Jason Burbank ${ }^{\mathrm{a}}$, Dragoljub B Kosanovic ${ }^{\mathrm{a}}$,

${ }^{a}$ Mechanical and Industrial Engineering, University of Massachusetts Amherst, U.S.

\section{ABSTRACT}

A control technique to optimize an existing de-coupled primary-secondary Ground Source Heat Pump (GSHP) loop system using site data is presented. The proposed control algorithm improves system performance by optimizing the primary loop pump's flow of well water into the secondary loop to deliver more favorable water temperatures to downstream heat pumps. Improvements are presented on a specific installation using 15-minute interval data collected from a building automation system (BAS) for a period of one year. Energy savings are calculated to demonstrate the benefits of improved heat transfer by modulating the building heat pumps condenser/evaporator entering water temperatures to improve COP. The specifics of how to implement this control scheme with an existing de-coupled GSHP system are provided. By monitoring the building HVAC operations, and optimizing the entering secondary loop water temperature, a 3\% decrease in annual heat pump energy consumption is achieved.

\section{Introduction}

In recent years GSHPs have become more common in the United States, Europe and Asia [1-2], due to their effectiveness in satisfying HVAC needs [3], where up to $70 \%$ of the energy consumed is energy recovered from the ground [4]. The principles and advantages of ground source heat pump technology have been described by Hanova at al. (2007), Spitler (2005), Halozan (2008), the Canadian GeoExchange Coalition (2007) and Canhoto et al. (2006). Even

\footnotetext{
${ }^{*}$ Corresponding author. Tel.: +1 5087177089

E-mail addresses: jmarmara@student.umass.edu (J Marmaras),

kosanovic@umass.edu (D Kosanovic),jburbank@facil.umass.edu (J Burbank)
} 
with higher installation costs [5], the energy benefits and potential for $\mathrm{CO}_{2}$ emission reduction [6] of GSHPs are significant enough to make GSHP systems cost-effective.

Recently, many studies have been performed to investigate the performance of GSHP systems under actual operating conditions (DiPippo (2015) [7], Michopulos at al., 2007 [8], Bi et al., 2009 [9], Kim et al., 2012[10], Self at al., 2013 [11]). Luo et al. 2015 [12] examined the thermal performance of a GSHP system in an office building in Nuremberg, Germany, continuously monitoring its performance for four years. Their results indicate that the GSHP system has a higher efficiency for building cooling than building heating. Magraner et al. (2010) [13] compared experimental results and design performance predictions for a GSHP in both heating and cooling modes. The main conclusion of their study was that simulation overestimates the measured overall energy performance by between $15 \%$ and $20 \%$.

Many other studies have tried to optimize the performance of GSHP systems based on computer simulation techniques (Zeng et al., 2003 [14]; Lee and Lam 2008 [15]). Several studies presented development of an analysis tool to predict performance of a GSHP. Nagano at al. 2006 [16] and Michopulos 2009 [17] developed a tool based on analytical equations describing the heat exchanged with the ground to determine heating and cooling needs of the building.

However very little work is available on energy consumption and optimization of the performance of existing GSHP systems. To fully understand the performance optimization of GSHP systems, a more comprehensive study is needed. In this paper, we examine thermal performance of a vertical GSHP system installed in an office building under actual energy demand of the building using collected data and Excel worksheets. A strategy is then proposed to optimize its performance that could be applied in many GSHP systems in operation today.

\section{System Configuration}


In May 2011, the University of Massachusetts (UMASS) Amherst began operation of its three story, 2,350 $\mathrm{m}^{2}\left(25,700 \mathrm{ft}^{2}\right)$ LEED Gold rated police station on campus. The building's HVAC systems include a decoupled primary-secondary GSHP loop in series with a dedicated outside air system (DOAS) roof top unit (RTU). The building's multiple zones are served by over forty individual heat pumps, which satisfy HVAC needs through recovering or discharging heat into the GSHP's secondary loop fluid . The primary loop acts as a heat source or sink for the GSHP's secondary loop to provide adequate cooling and heating for all of the local heat pumps and the RTU, as seen in Figure 1. The RTU utilizes two $44 \mathrm{~kW}$ scroll compressors fed by fluid from the GSHP secondary loop to condition the outside air. The RTU then provides air to all 41 zones. Each zone is equipped with a dual capacity heat pump, with units varying in size from 1.75 to $10.5 \mathrm{~kW}$. Each heat pump can operate in either heating or cooling mode, depending on its zone requirements. In all there are nine $1.75 \mathrm{~kW}$, nine $3.5 \mathrm{~kW}$, ten $5.25 \mathrm{~kW}$, ten $7 \mathrm{~kW}$, and three $10.5 \mathrm{~kW}$ units, each with a COP performance curver for both heating and cooling conditions. The temperature of the GSHP fluid entering the building via the secondary building loop will be referred to as the entering water temperature (EWT) as seen in Figure 1. The temperature of fluid returning from the HVAC components and leaving the building via the secondary GSHP loop will be referred to as the leaving water temperature (LWT). The available (ground) well fluid temperature within the primary loop of the GSHP system will be referred to as the well water temperature (WWT).

Currently, the primary loop pump operates when the EWT travels outside set point conditions. This paper will show that allowing the EWT to follow closely the WWT, by maintaining the flow of well water through the secondary loop, COP is improved and pumping costs are reduced.

The GSHP loop data provides information on the net heating or cooling load of the entire 
facility via the secondary loop temperatures. The secondary loop's EWT, LWT, and flow can indicate the "dominating" load for the building. If the EWT $>$ LWT, then the overall building is in heating mode, and if the LWT $>$ EWT then the building requires cooling; if the EWT equals the LWT, the building is experiencing a balanced load of both heating and cooling. The cooling and heating cycles' energy performance is measured by the unit's coefficient of performance (COP), defined in equation (1), where the actual power output reflects the units heating/cooling energy based on manufacturers performance curves at various conditions:

$$
\text { COP }=\frac{\text { Actual Variable Output }}{\text { Equipment Power Input }}
$$

Figure 1 shows one possible setup for a decoupled primary-secondary GSHP Loop. This diagram shows the vertical wells where flow through the ground is controlled via the primary loop pump. The secondary loop then circulates fluid throughout the facility via the secondary loop pump to provide fluid to the building's HVAC equipment. Figure 1 also shows the locations of the differential pressure (Dp) sensors whose purpose is to provide a control signal, and change the pump's speed via VFD depending on the number of components that call for flow (HVAC equipment has three way valves).

\section{Current Primary-Secondary GSHP Loop EWT Control Theory}

GSHP systems typically utilize one main loop to accomplish heat transfer between the HVAC equipment and the ground for both cooling and heating operations [18]. The decoupled primary-secondary loop system is designed to take advantage of the anticipated balanced heating and cooling loads throughout the building. In the winter, for example, solar gains in spaces with south-facing windows and heat gains from occupants in interior spaces, could require cooling in some zones [19]. This scheme helps eliminate extra pumping in the primary loop during shoulder seasons and at times when zone requirements differ [20]. 
The control scheme for the current de-coupled primary-secondary GSHP loop operation allows the secondary loop water temperature to float within a temperature control band. When the EWT migrates outside the control range set point of 4.4 to $23.8^{\circ} \mathrm{C}\left(40\right.$ to $\left.75^{\circ} \mathrm{F}\right)$, the primary loop pump will turn on and provide flow. This introduces well water to the secondary loop, causing the entering water temperature to either reduce or increase the secondary loop's EWT as needed. The secondary pump never shuts off due to continuous HVAC load within the building, and required minimum flow to avoid equipment alarms. The disadvantage to this control system is that the optimal performance of the downstream HVAC equipment is never taken into account.

Table 1 below shows the primary and secondary pump speeds for the particular building considered for this study. Data indicates the primary pump often provided more flow than required by the secondary loop, resulting in unnecessary recirculation and increased energy use.

It should be noted that due to the nature of the decoupled system, the primary pump should never provide more flow than the secondary loop requires. This will minimize energy use and avoid unnecessary recirculation. Based upon current operating conditions, the primary pump could operate all year at $60 \%$ flow reducing current pump energy $15 \%$ or approximately 2,000 $\mathrm{kWh}$ while satisfying the needs of the system. Therefore the pump energy would not be negatively impacted due to the control algorithm proposed in this paper.

\subsection{Coefficient of Performance Calculations}

As the EWT fluctuates, so does the performance of the HVAC equipment conditioning the building, providing an opportunity to improve performance [21]. Allowing EWT to follow WWT will improve the COP of all the operating compressors [22], and reduce the building HVAC equipment's overall power consumption [23]. The COP to energy efficiency ratio (EER) (EER = $\mathrm{COP} / 3.412$ ) rating data can be compiled to construct performance curves based on various EWT conditions. This allows for COP analysis at any given time, temperature, and load. Figure 2 
shows an example of the polynomial curve fits for the manufacturer's COP versus EWT used for calculations [24].

The COP curve fit equations developed for all components was used to determine the performance of the primary-secondary GSHP system for the year. The building is equipped with a building automation system (BAS) for monitoring purposes. The BAS provides information on temperature, humidity, air flow, water flow, fan and pump speeds from sensors for all sections of the HVAC system including the primary-secondary GSHP loop. The historical data was instrumental in benchmarking the performance of the current control strategy.

\subsection{Benchmarking Current GSHP System Performance}

In order to benchmark the current primary-secondary GSHP system performance, BAS data was collected for all HVAC systems. This included data for the GSHP well temperature (WWT) and the secondary loop's entering (EWT) and leaving (LWT) water temperatures along with the on/off status and the heating/cooling status for each piece of HVAC equipment.

The power required to operate all working compressors in the building at any given time will be determined by summing the input power for all compressors. Power draw for compressors in both heating and cooling modes will be determined in order to demonstrate possible improvements in performance for the entire system. During transitional periods and shoulder months, reducing the secondary GSHP loop's EWT will increase the COP of compressors in cooling mode while adversely affecting the COPs of units in heating mode. This will be accounted for in equation (2).

$$
\text { Power }_{\text {input }}=\left(\text { Power }_{\text {cooling }}+\text { Power }_{\text {heating }}\right)
$$

To determine the input power required for all working compressors, the units in heating and cooling mode will need to be identified using the BAS data [25]. The rated output power for working compressors is then divided by the overall weighted COP for working compressors in 
both heating and in cooling mode, as seen in equation (3).

$$
\text { Power }_{\text {input }}=\left.\left[\left(\frac{\sum_{i=1}^{n}\left(\mathrm{RP}_{i}\right)}{\left(\mathrm{COP}_{\text {weighted }}\right)_{\text {cooling }}}\right)_{\text {cooling }}+\left(\frac{\sum_{i=1}^{n}\left(\mathrm{RP}_{i}\right)}{\left(\mathrm{COP}_{\text {weighted }}\right)_{\text {heating }}}\right)_{\text {heating }}\right]\right|_{\text {EWT/WWT }}
$$

$i \equiv$ all HVAC compressors within the building

$\mathrm{RP}_{i} \equiv$ rated power of $i^{\text {th }}$ compressor in $\mathrm{kW}\left(\mathrm{RP}_{i}=0\right.$ if compressor is off)

To accurately determine the weighted COP (heating/cooling) for all compressors operating at any given time in cooling and in heating modes, equation (4) will be used. For this equation, the COP is calculated for each compressor size based on the EWT. The COPs are then normalized by their respective rated output power to avoid smaller units dominating the calculated COP of the system.

$$
\mathrm{COP}_{\text {weighted }}=\left.\left(\frac{\sum_{i=1}^{n}\left(\mathrm{RP}_{i} \times \mathrm{COP}_{\text {compressor }}\right)}{\sum_{i=1}^{n}\left(\mathrm{RP}_{i}\right)}\right)\right|_{\text {cooling/heating }}
$$

To determine the COP for each piece of equipment operating in either heating or cooling mode, COP curve fit equations for each unit are used. COP curves should be generated for each size of compressor for both the heating and cooling modes of operation and as a function of EWT (or possibly WWT) to the unit, which is denoted in equation (5) below.

$$
\mathrm{COP}_{\text {Compressor }_{i}}=\left.\mathrm{COP}[f(\mathrm{EWT})]\right|_{\text {EWT/WWT-curve fit equation as function of EWT }}
$$

The HVAC equipment data, collected in 15-minute intervals for an entire year, was then compiled to construct COP versus EWT curves for each unit. This is done for both heating and cooling operation for all HVAC systems to determine an overall COP[26]. 
The results for the benchmarked building HVAC equipment performance can be observed in Table 2. Data has been averaged on a monthly basis for both the cooling and heating operations.

\subsection{Proposed Secondary Pumping Loop EWT Control}

The EWT is a result of interaction between the building's HVAC loads, the outside air conditions and the primary well pump ground conditions. The primary well pump operation is dictated by the fixed operating temperature band of the secondary loop. Data collected from the BAS has shown this to be a less-than optimal scheme for HVAC systems in terms of the delivered EWT, each unit's performance, and the overall system performance. For example, during the summer months when the temperature of the EWT exceeds the $23.8^{\circ} \mathrm{C}\left(75^{\circ} \mathrm{F}\right)$ set point, the primary pump turns on and provides cooler fluid to decrease the EWT back within the temperature set point range. As a result, the EWT will drop down to $23.3-23.8^{\circ} \mathrm{C}\left(74-75^{\circ} \mathrm{F}\right)$ with a set point of $24^{\circ} \mathrm{C}\left(75^{\circ} \mathrm{F}\right)$ before the primary pump shuts off. If the EWT were allowed to drop further and follow the WWT, it would improve the system COP reducing energy consumption. In addition, the existing scheme results in the primary pump cycling on and off more often to maintain a $23.8^{\circ} \mathrm{C}$ temperature set-point. Running the primary pump longer at reduced speeds and eliminating any recirculation would decrease the secondary loop EWT to match the WWT, which in some cases is more than $5^{\circ} \mathrm{C}\left(10^{\circ} \mathrm{F}\right)$ cooler. The more favorable temperature would improve the cooling COP performance, and reduce energy consumption of the HVAC unit's compressor [27]. Figure 3 below shows the different conditions where the opportunity exists to reduce HVAC energy consumption by increasing the equipment's COP through optimal EWT.

Control strategies in the past have tended to avoid methods that rely on a constant temperature set-point [28]. Typically systems use a constant flow loop where the flow is controlled according to the temperature differential between the entering and leaving water conditions. This approach is flawed when there is a balanced load, as the temperature differential 
is close to zero, resulting in no flow to the operating units. For the system considered here, the secondary pumps are controlled according to the differential pressure, ensuring there is enough flow for the HVAC equipment to operate properly.

The temperature control strategy would be specifically applied for the primary loop which is directly piped into the secondary loop. In this system, the WWT can be directly introduced to the secondary loop, allowing for the EWT to be affected almost instantaneously. Figure 3 shows that there were many instances in which the primary loop's WWT was more favorable than that of the secondary loop EWT during both the cooling and heating seasons. Calculations show that with equipment fully loaded for either heating or cooling, a $0.6^{\circ} \mathrm{C}\left(1^{\circ} \mathrm{F}\right)$ change in temperature would increase the COP and reduce the system power draw by up to $1 \mathrm{~kW}$ (Table 2).

\subsection{Projected Results of Re-programming GSHP Controls:}

The BAS data was compiled to construct COP versus EWT curves for all HVAC equipment. Equation (7) demonstrates how this particular building's HVAC equipment fits into equation (3).

$$
\begin{aligned}
& \text { Power }_{\text {input output }}=\left[\left.\left(\frac{\mathrm{RP}_{1.75 \mathrm{~kW} \mathrm{Unit}}+\mathrm{RP}_{3.5 \mathrm{~kW} \mathrm{Unit}}+\mathrm{RP}_{5.25 \mathrm{~kW} \mathrm{Unit}}+\mathrm{RP}_{7.0 \mathrm{~kW} \mathrm{Unit}}+\mathrm{RP}_{10.5 \mathrm{~kW} \text { Unit }}+\ldots . .}{\left(\frac{\left(\mathrm{RP}_{1.75 \mathrm{~kW} \text { Unit }} \times \mathrm{COP}_{1.75 \mathrm{~kW} \text { Unit }}\right)+\left(\mathrm{RP}_{3.5 \mathrm{~kW} \mathrm{Unit}} \times \mathrm{COP}_{3.5 \mathrm{~kW} \text { Unit }}\right)+\ldots . .}{\left(\mathrm{RP}_{1.75 \mathrm{~kW} \text { Unit }}+\mathrm{RP}_{3.5 \mathrm{~kW} \mathrm{Unit}}+\mathrm{RP}_{5.25 \mathrm{~kW} \mathrm{Unit}}+\mathrm{RP}_{7.0 \mathrm{~kW} \text { Unit }}+\ldots . .\right)}\right)}\right)\right|_{\text {EWT }}\right]_{\text {cooling }} \\
& +\left[\left(\left.\frac{\mathrm{RP}_{1.75 \mathrm{~kW} \text { Unit }}+\mathrm{RP}_{3.5 \mathrm{~kW} \text { Unit }}+\mathrm{RP}_{5.25 \mathrm{~kW} \mathrm{Unit}}+\mathrm{RP}_{7.0 \mathrm{~kW} \text { Unit }}+\mathrm{RP}_{10.5 \mathrm{~kW} \text { Unit }}+\ldots . .}{\left(\frac{\left(\mathrm{RP}_{1.75 \mathrm{~kW} \text { Unit }} \times \mathrm{COP}_{1.75 \mathrm{~kW} \mathrm{Unit}}\right)+\left(\mathrm{RP}_{3.5 \mathrm{~kW} \text { Unit }} \times \mathrm{COP}_{3.5 \mathrm{~kW} \mathrm{Unit}}\right)+\ldots . .}{\left(\mathrm{RP}_{1.75 \mathrm{~kW} \text { Unit }}+\mathrm{RP}_{3.5 \mathrm{~kW} \text { Unit }}+\mathrm{RP}_{5.25 \mathrm{~kW} \text { Unit }}+\mathrm{RP}_{7.0 \mathrm{~kW} \mathrm{Unit}}+\ldots . .\right)}\right)}\right|_{\text {EWT }}\right]_{\text {heating }}\right.
\end{aligned}
$$

This equation calculates the instantaneous power draw at any given time and is used to determine energy saved over time by the HVAC equipment through the new control algorithm.

The proposed operation involves a control algorithm that takes into account all the building systems, whether in cooling or heating mode, and determines the building weighted COP and actual energy input. This procedure will help determine when to introduce the WWT into the 
secondary loop via the primary loop pump. The proposed algorithm can also help determine proposed energy consumption by indicating how the GSHP loop is performing.

\subsection{Primary Pump Control Algorithm}

To determine whether to introduce the WWT, the compressors' input power will be calculated based on COP. Calculations will be performed for the current EWT and for the WWT available. The proposed operation would involve the following sequence:

- Monitor the secondary GSHP loop's EWT vs. LWT and determine the dominant building load; i.e., heating, cooling, or balanced (no temperature differential)

- When in heating or cooling load (defined by $>0.6^{\circ} \mathrm{C}$ differential), compare primary GSHP loop WWT with current EWT of the secondary loop

- For heating mode (WWT $>$ EWT), and for cooling mode (EWT $>$ WWT): run algorithm to determine if the opportunity exists to reduce system power consumption by comparing building COP under existing and new operating conditions

Figure 4 flow chart shows the logic for the algorithm described.

The sequence will determine if the building compressors would require less power to run, and if the COP would be improved by introducing the primary GSHP loop's WWT. If equation (8) is true, then the primary pump should operate to provide the WWT fluid to the secondary loop (at a flow rate equal to the secondary loop flow rate).

$$
\left.\left(\text { Power }_{\text {input }}\right)\right|_{\mathrm{WWT}}<\left.\left(\text { Power }_{\text {input }}\right)\right|_{\mathrm{EWT}}
$$

A sensitivity analysis for this algorithm was performed by increasing/decreasing the EWT (depending on the building load) in $0.6^{\circ} \mathrm{C}\left(1^{\circ} \mathrm{F}\right)$ increments to determine the relationship between the building COP and power consumption. The BAS data suggests that, during the winter and summer months, the building typically operated at 50\% $-75 \%$ of its rated capacity. During the shoulder months it was shown that the dominating load (either heating or cooling) operated close to $50 \%$ capacity, while the secondary load operated between $10 \%$ and $25 \%$ of the rated capacity. Table 2 shows the results of a sensitivity analysis performed to determine the potential energy 
savings associated with increasing and decreasing the secondary loop EWT by introducing WWT fluid from the primary loop. It can be observed that there is much greater opportunity for performance improvements during cooling operations.

A real-time simulation was then performed using the 15-minute BAS data. The EWT was compared to the potential WWT available in the primary GSHP loop (equation 8). This analysis determines when to implement the control algorithm. Figure 5 is a graph of the results over a year for the potential power savings. It is observed that the greatest savings occur during the shoulder months and the summer months.

During the summer months, the temperature differential between the EWT and WWT is lower, but large energy savings result due to the many HVAC units in operation. This data shows little opportunity for savings during the winter months. This might be due to the mild weather during the year for which data was available, resulting in low energy consumption.

After the simulation was completed for each time step, all data, for the EWT and LWT for either cooling or heating modes, was averaged on a monthly basis. The associated power savings from utilizing the WWT fluid to increase the HVAC systems' COP was also averaged on a monthly basis for that year and shown in Table 3 .

There is an opportunity for the use of this optimized EWT control for systems with a decoupled primary-secondary GSHP loop configuration. There were savings of approximately $3 \%$ on the cooling side and $1 \%$ on the heating side for the compressor energy used during the entire year-long simulation. It is likely that winter savings would be greater in a more seasonable winter [29]. Results also show that the greatest potential exists during shoulder and summer months to optimize a decoupled GSHP system to achieve additional performance improvement and energy savings. 
In order to demonstrate the proposed control algorithm and the impacts on energy consumption, results for two different periods during the summer are presented. A five-day period in June was analyzed when the outside temperature was mild, along with a four-day period in July during a heat wave. During the June period, there was a greater temperature differential for the WWT versus the EWT, but due to the mild outside temperature, not as many compressors were operating. This resulted in a higher percent increase in the COP for a reduced compressor load which resulted in an average $2.04 \mathrm{~kW}$ power savings. During the July heat wave, the temperature differential of the WWT versus the EWT had less potential, but more of the HVAC compressors were operating. This resulted in a lower percent increase in COP but for a higher compressor load which resulted in an average $1.45 \mathrm{~kW}$ power savings during that time. Results for both simulations can be viewed in Figure 6.

This analysis shows that there is potential for the control algorithm to be applied when the HVAC loads within the building are small due to mild weather and when loads are high due to extreme weather conditions.

\section{Discussion/Conclusion}

As designers strive to make buildings more energy efficient, control strategies and system operations must be optimized in order to achieve energy improvements. Optimizing the EWT through the logic sequence of the primary-secondary loop GSHP operations is shown to measurably impact the performance of the HVAC system compressors, and to improve system COP. In this case there was an increase in both the operating COP and the EER of the system. Pumping power was determined to not be a major factor due to the current cycling operation verse the proposed part load operation. The proposed control strategy optimization indicates a 2-

$3 \%$ reduction in building energy consumption by implementation of a sliding temperature control 
sequence for the EWT of the secondary loop. This would benefit the building's overall system

efficiency.

\section{References}

[1] W. Yang, J. Zhou, W. Xu, G. Zhang, Current status of ground-source heat pumps in China, Energy Policy 38 (2010) 323-332.

[2] J. Lee, Current status of ground-source heat pumps in Korea, Renewable and Sustainable Energy Reviews 13 (2009) 1560-1568.

[3] J.W. Lunda, D.H. Freestonb, T.L. Boyd, Direct utilization of geothermal energy 2010 worldwide review, Geothermics 40 (2011) 159-180.

[4] K.J. Chua, S.K. Chou, W.M. Yang, Advances in heat pump systems; A review, Applied Energy 87 (2010) 3611-3624.

[5] F. Robert, L. Gosselin, New methodology to design ground coupled heat pump systems based on cost minimization, Applied Thermal Engineering 62 (2014) 481-491.

[6] N. Pardo, Z. Montero, J.F. Urchueguia, Optimization of hybrid - ground source and air source - heat pump systems in combination with thermal storage, Applied Thermal Engineering 30 (2010) 1073-1077.

[7] Ronald DiPippo, Geothermal power plants: Evaluation and performance assessment, Geothermics 53 (2015) 291-307.

[8] A. Michopoulos, D. Bozis, P. Kikidis, K. Papakostas, N.A. Kyriakis, Three-years operation experience of a ground source heat pump system in Northern Greece, Energy and Buildings 39 (2007) 328-334.

[9] Yuehong Bi, Xinhong Wang, Yun Liu, Hua Zhang, Lingen Chen, Comprehensive exergy analysis of a ground-source heat pump system for both building heating and cooling modes, Applied Energy 86 (2009) 2560-2565.

[10] Euiyoung Kim, Jaekeun Lee, Youngman Jeong, Yujin Hwang,*, Sangheon Lee, Naehyun Park, Performance evaluation under the actual operating condition of a vertical ground source heat pump system in a school building, Energy and Buildings 50(2012) 1-6.

[11] S.J. Self, B.V. Reddy, M.A. Rosen, Ground source heat pumps for heating: Parametric energy analysis of a vapor compression cycle utilizing an economizer arrangement, Applied Thermal Engineering 52 92013) 245-254.

[12] J. Luo, J. Rohn, M. Bayer, A. Priess, L. Wilkmann, W. Xiang, Heating and cooling performance analysis of a ground source heat pump system in Southern Germany, Geothermics 53 (2015) 57-66. 
[13] T. Magraner, A. Montero, S. Quilis, J.F. Urchueguía, Comparison between design and actual energy performance of a HVAC-ground coupled heat pump system in cooling and heating operation, Energy and Buildings 42 (2010) 1394-1401.

[14] Heyi Zeng, Nairen Diao, Zhaohong Fang, Heat transfer analysis of boreholes in vertical ground heat exchangers, International Journal of Heat and Mass Transfer 46 (2003) 4467-4481.

[15] C.K. Lee, H.N. Lam, Computer simulation of borehole ground heat exchangers for geothermal heat pump systems, Renewable Energy 33 (2008), 1286-1296.

[16] K. Nagano, T. Katsura and S. Takeda, Development of a design and performance prediction tool for the ground-source heat pump system, Applied Thermal Engineering 26 (2006) 15781592.

[17] A. Michopoulos, N. Kyriakis, A new energy analysis tool for ground source heat pump systems, Energy and Buildings 41 (2009) 937-941.

[18] H. Madani, J. Claesson, P. Lundqvist, A descriptive and comparative analysis of three common control techniques for an on/off controlled Ground Source Heat Pump (GSHP) system, Energy and Builidngs 65 (2013) 1-9.

[19] O. Zogou, A. Stamatelos, Optimization of thermal performance of a building with ground source heat pump system, Energy and Conservation Management 48 (2007) 2853-2863.

[20] S. Kavanaugh, Less Pumping Means Cooler Ground Loops, ASHRAE Journal July (2011) 26-35.

[21] S. Kavanaugh, Commercial GSHP performance part 2: ground loops, pumps, ventilation and air control, ASHRAE Journal July (2012) 27-34.

[22] O. Ozgener, A. Hepbasli, Modeling and performance evaluation of ground source (geothermal) heat pump systems, Energy and Buildings 39 (2007) 66-75.

[23] M. Inalli, H. Esen, Experimental thermal performance evaluation of a horizontal ground source heat pump system, Applied Thermal Engineering 24 (2004) 2219-2232.

[24] Johnson Controls.(2008). Water Source Heat pumps. Milwaukee, WI.

[25] J. Plourde, Making the case for energy metering, ASHRAE Journal April (2011) 20-28.

[26] A. Hepbasli, O. Akdemir, E. Hancioglu, Experimental study of a closed loop vertical ground-source heat pump system, Energy Conservation and Management 44 (2003) 527-548.

[27] O. Zogou, A. Stamatelos, Optimization of thermal performance of a building with ground source heat pump system, Energy and Conservation Management 48 (2007) 2853-2863.

[28] K. Rafferty, Design Issues in the Commercial Application of GSHP Systems in the U.S., GHC Bulletin, March (2000) 6-10. 
[29] K. Bakirci, Evaluation of the performance of a ground-source heat pump system with series ground heat exchanger in the cold climate region, Energy 35 (2010) 3088-3096. 
Fig. 1. Diagram of the primary-secondary pumping scheme as configured in the BAS. Arrows indicate the direction of water flow and the EWT/LWT/WWT bullets indicate where the BAS measures water temperature

Fig. 2. COP curves for various EWT for all heat pumps in heating and cooling modes of operation.

Fig. 3. Sample of opportunities that exist with increasing the COP through introducing the WWT to the secondary GSHPs loop for both heating and cooling modes: Notice heating shows the least amount of opportunity for this system.

Fig. 4. Flow chart to show logic of proposed algorithm which will introduce the primary loop water into the secondary loop to improve the COP of the system and reduce energy consumption

Fig. 5. Algorithm results using real time actual data collected from the BAS. Notice the most opportunities are found during the shoulder and summer months

Fig. 6. Analysis results for two periods of the year with the proposed control algorithm. The June period had milder weather with a reduced HVAC load where the July period experienced a heat wave with a high HVAC load 
Table 1. Annual Operating Speeds for Primary and Secondary GSHP Loop Pumps. The primary pumps operation is off for approximately $23 \%$ of the year.

Table 2. Energy Performance of Building's HVAC Equipment for the Current Secondary Loop EWT Control. Temperatures and COP Ratings are the Average Over the Month for the Given Cooling/Heating Loads

Table 3. Sensitivity analysis of opportunities that exist with increasing the COP through introducing the WWT to the secondary GSHPs loop for both heating and cooling modes

Table 4. Results of implementing real time algorithm with building 15 minute data, shows actual average temperatures and power savings during heating and cooling loads. 


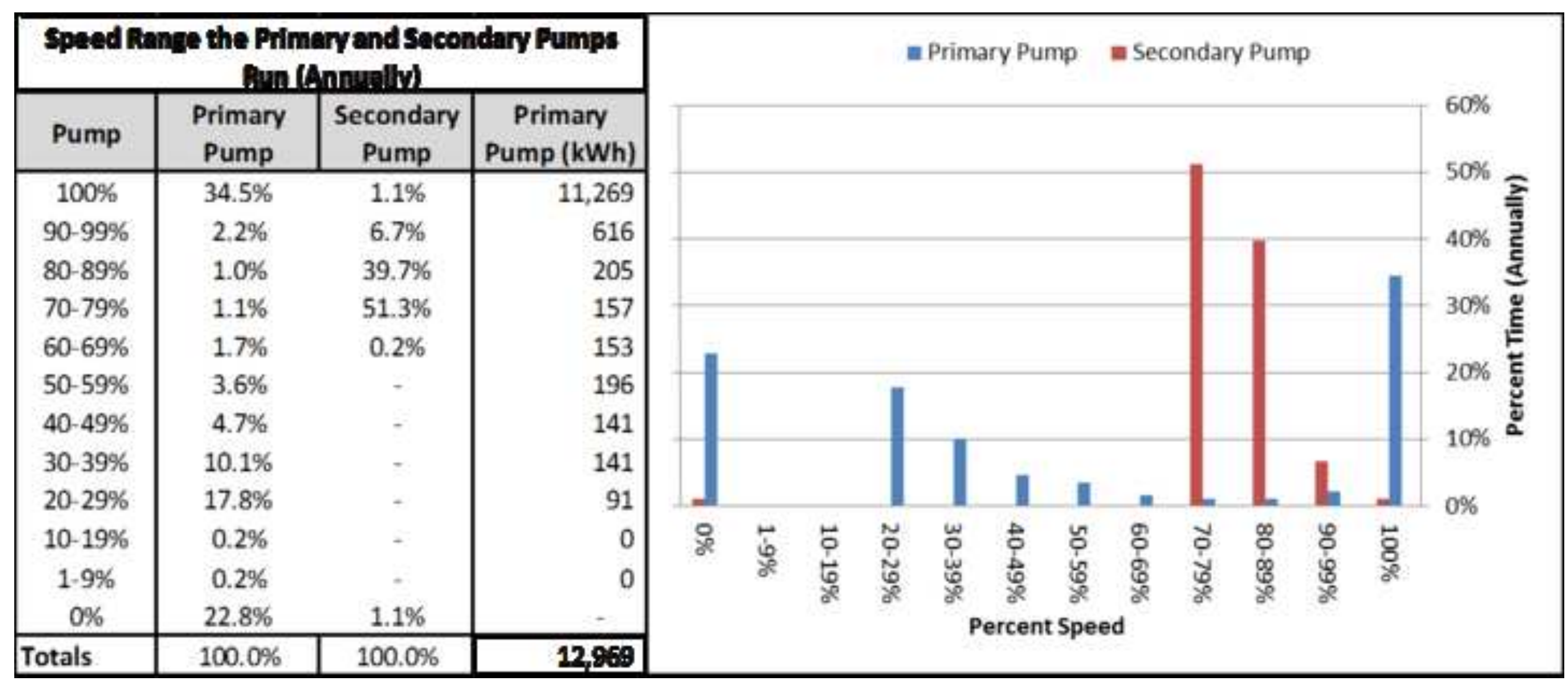




\begin{tabular}{|c|c|c|c|c|c|c|c|}
\hline \multirow[b]{2}{*}{ Year } & \multirow{3}{*}{ Month } & \multicolumn{6}{|c|}{ Current Secondary Loop Operation EWT } \\
\hline & & \multicolumn{3}{|c|}{ Actual Heating Mode Operation } & \multicolumn{3}{|c|}{ Actual Cooling Mode Operation } \\
\hline & & ${ }^{\circ} \mathrm{F}$ & Hours & COP & ${ }^{\circ} \mathrm{F}$ & Hours & COP \\
\hline \multirow[t]{9}{*}{2011} & April & 49.3 & 292.8 & 3.99 & 63.5 & 252.0 & 5.64 \\
\hline & May & 52.7 & 19.8 & 4.17 & 66.2 & 674.5 & 5.30 \\
\hline & June & 66.7 & 1.5 & 4.59 & 70.3 & 640.0 & 4.94 \\
\hline & July & - & 0.0 & - & 73.7 & 744.0 & 4.72 \\
\hline & August & - & 0.0 & - & 74.5 & 632.5 & 4.68 \\
\hline & September & 55.6 & 2.8 & 4.27 & 72.5 & 677.5 & 4.77 \\
\hline & October & 48.3 & 50.0 & 3.91 & 74.8 & 534.8 & 4.62 \\
\hline & November & 49.4 & 157.0 & 4.01 & 73.1 & 314.8 & 4.68 \\
\hline & December & 47.1 & 573.8 & 3.91 & 72.3 & 47.3 & 4.62 \\
\hline \multirow[t]{4}{*}{2012} & January & 47.9 & 586.5 & 3.97 & 67.9 & 24.5 & 4.99 \\
\hline & February & 48.1 & 205.3 & 3.90 & 68.1 & 141.5 & 5.09 \\
\hline & March & 47.3 & 163.3 & 3.86 & 72.8 & 378.0 & 4.78 \\
\hline & TOTALS & & $2,052.5$ & & & $5,061.3$ & \\
\hline
\end{tabular}




\begin{tabular}{ccc}
\hline \multicolumn{3}{c}{ Energy Consumption } \\
\hline \hline $\begin{array}{c}\text { Heating Energy } \\
\text { Consumption }\end{array}$ & $\begin{array}{c}\text { Cooling Energy } \\
\text { Consumption }\end{array}$ & $\begin{array}{c}\text { Total HVAC Energy } \\
\text { Consumption }\end{array}$ \\
\hline \hline (kWh) & (kWh) & (kWh) \\
\hline \hline 11,431 & 9,091 & $20,521.7$ \\
1,892 & 19,997 & $21,889.0$ \\
382 & 21,861 & $22,243.1$ \\
5 & 27,322 & $27,326.6$ \\
28 & 24,500 & $24,527.8$ \\
545 & 21,177 & $21,721.7$ \\
4,043 & 15,587 & $19,630.0$ \\
8,454 & 9,030 & $17,483.5$ \\
18,150 & 1,190 & $19,340.6$ \\
18,336 & 1,865 & $20,201.8$ \\
10,893 & 3,140 & $14,033.6$ \\
8,324 & 10,284 & $18,607.9$ \\
\hline 82,484 & 165,043 & $\mathbf{2 4 7 , 5 2 7}$ \\
\hline
\end{tabular}




\begin{tabular}{|c|c|c|c|c|c|}
\hline \multicolumn{6}{|c|}{ COOLING (Summer Months - Dominant Load) } \\
\hline $\begin{array}{c}\text { Average } \\
\text { EWT (BAS } \\
\text { data) }\end{array}$ & $\begin{array}{c}\text { Temperature } \\
\text { Decrease }\end{array}$ & $\begin{array}{l}\text { Overall } \\
\text { Building } \\
\text { COP }\end{array}$ & $\begin{array}{c}\text { COP } \\
\text { Improvement }\end{array}$ & $\begin{array}{l}\text { (75\%) Loaded } \\
\text { System Power } \\
\text { Savings }\end{array}$ & $\begin{array}{l}\text { (50\%) Loaded } \\
\text { System Power } \\
\text { Savings }\end{array}$ \\
\hline${ }^{\circ} \mathrm{C}$ & ${ }^{\circ} \mathrm{C}$ & - & $(\%)$ & $(\mathrm{kW})$ & $(\mathrm{kW})$ \\
\hline 23.6 & 0 & 4.65 & $0.0 \%$ & 0.0 & 0.0 \\
\hline 23.6 & 0.6 & 4.71 & $1.4 \%$ & 0.6 & 0.5 \\
\hline 23.6 & 1.1 & 4.77 & $2.8 \%$ & 1.2 & 0.9 \\
\hline 23.6 & 1.7 & 4.84 & $4.1 \%$ & 1.7 & 1.3 \\
\hline 23.6 & 2.2 & 4.90 & $5.4 \%$ & 2.3 & 1.7 \\
\hline 23.6 & 2.8 & 4.96 & $6.7 \%$ & 2.8 & 2.1 \\
\hline 23.6 & 3.3 & 5.02 & $8.0 \%$ & 3.3 & 2.5 \\
\hline 23.6 & 3.9 & 5.09 & $9.5 \%$ & 3.9 & 2.9 \\
\hline 23.6 & 4.4 & 5.16 & $11.0 \%$ & 4.4 & 3.3 \\
\hline 23.6 & 5 & 5.23 & $12.6 \%$ & 5.0 & 3.8 \\
\hline 23.6 & 5.6 & 5.31 & $14.3 \%$ & 5.6 & 4.2 \\
\hline \multicolumn{6}{|c|}{ Cooling (Shoulder Seasons - Balanced Loads) } \\
\hline $\begin{array}{c}\text { Average } \\
\text { EWT (BAS } \\
\text { data) }\end{array}$ & $\begin{array}{c}\text { Temperature } \\
\text { Decrease }\end{array}$ & $\begin{array}{l}\text { Overall } \\
\text { Building } \\
\text { COP }\end{array}$ & $\begin{array}{c}\text { COP } \\
\text { Improvement }\end{array}$ & $\begin{array}{c}\text { (50\% cool to } \\
10 \% \text { heat) } \\
\text { Loaded System } \\
\text { Power Savings }\end{array}$ & $\begin{array}{c}\text { (50\% cool to } \\
25 \% \text { heat) } \\
\text { Loaded System } \\
\text { Power Savings }\end{array}$ \\
\hline${ }^{\circ} \mathrm{C}$ & ${ }^{\circ} \mathrm{C}$ & - & $(\%)$ & $(\mathrm{kW})$ & $(\mathrm{kW})$ \\
\hline 23.6 & 0 & 4.66 & $0.2 \%$ & 0.0 & 0.0 \\
\hline 23.6 & 0.6 & 4.72 & $1.5 \%$ & 0.4 & 0.4 \\
\hline 23.6 & 1.1 & 4.77 & $2.7 \%$ & 0.9 & 0.8 \\
\hline 23.6 & 1.7 & 4.83 & $3.9 \%$ & 1.3 & 1.2 \\
\hline 23.6 & 2.2 & 4.88 & $5.1 \%$ & 1.6 & 1.5 \\
\hline 23.6 & 2.8 & 4.94 & $6.3 \%$ & 2.0 & 1.9 \\
\hline 23.6 & 3.3 & 5.00 & $7.6 \%$ & 2.4 & 2.2 \\
\hline 23.6 & 3.9 & 5.06 & $8.9 \%$ & 2.8 & 2.6 \\
\hline 23.6 & 4.4 & 5.12 & $10.3 \%$ & 3.2 & 3.0 \\
\hline 23.6 & 5 & 5.19 & $11.8 \%$ & 3.6 & 3.4 \\
\hline 23.6 & 5.6 & 5.27 & $13.3 \%$ & 4.1 & 3.7 \\
\hline
\end{tabular}




\begin{tabular}{|c|c|c|c|c|c|}
\hline \multicolumn{6}{|c|}{ HEATING (Winter Months - Dominant Load) } \\
\hline $\begin{array}{c}\text { Average EWT } \\
\text { (BAS data) }\end{array}$ & $\begin{array}{l}\text { Temperature } \\
\text { Increase }\end{array}$ & $\begin{array}{c}\text { Overall } \\
\text { Building COP }\end{array}$ & $\begin{array}{c}\text { COP } \\
\text { Improvement }\end{array}$ & $\begin{array}{l}\text { (75\%) Loaded } \\
\text { System Power } \\
\text { Savings }\end{array}$ & $\begin{array}{l}\text { (50\%) Loaded } \\
\text { System Power } \\
\text { Savings }\end{array}$ \\
\hline${ }^{\circ} \mathrm{C}$ & ${ }^{\circ} \mathrm{C}$ & - & $(\%)$ & $(\mathrm{kW})$ & $(\mathrm{kW})$ \\
\hline 8.1 & 0 & 3.80 & $0.4 \%$ & 0.0 & 0.0 \\
\hline 8.1 & 0.6 & 3.84 & $1.4 \%$ & 0.5 & 0.4 \\
\hline 8.1 & 1.1 & 3.88 & $2.5 \%$ & 1.0 & 0.7 \\
\hline 8.1 & 1.7 & 3.93 & $3.7 \%$ & 1.5 & 1.1 \\
\hline 8.1 & 2.2 & 3.97 & $4.8 \%$ & 2.0 & 1.5 \\
\hline 8.1 & 2.8 & 4.01 & $6.0 \%$ & 2.4 & 1.8 \\
\hline 8.1 & 3.3 & 4.06 & $7.1 \%$ & 2.9 & 2.1 \\
\hline 8.1 & 3.9 & 4.10 & $8.2 \%$ & 3.3 & 2.5 \\
\hline 8.1 & 4.4 & 4.14 & $9.3 \%$ & 3.8 & 2.8 \\
\hline 8.1 & 5 & 4.18 & $10.4 \%$ & 4.2 & 3.1 \\
\hline 8.1 & 5.6 & 4.22 & $11.5 \%$ & 4.6 & 3.4 \\
\hline \multicolumn{6}{|c|}{ Heating (Shoulder Seasons - Balanced Loads) } \\
\hline $\begin{array}{l}\text { Average EWT } \\
\text { (BAS data) }\end{array}$ & $\begin{array}{c}\text { Temperature } \\
\text { Increase }\end{array}$ & $\begin{array}{c}\text { Overall } \\
\text { Building COP }\end{array}$ & $\begin{array}{c}\text { COP } \\
\text { Improvement }\end{array}$ & $\begin{array}{c}\text { (50\% heat to } \\
10 \% \text { cool) } \\
\text { Loaded System } \\
\text { Power Savings } \\
\end{array}$ & $\begin{array}{c}\text { (50\% heat to } \\
25 \% \text { cool) } \\
\text { Loaded System } \\
\text { Power Savings } \\
\end{array}$ \\
\hline${ }^{\circ} \mathrm{C}$ & ${ }^{\circ} \mathrm{C}$ & - & $(\%)$ & $(\mathrm{kW})$ & $(\mathrm{kW})$ \\
\hline 10 & 0 & 4.41 & $0.4 \%$ & 0.0 & 0.0 \\
\hline 10 & 0.6 & 4.42 & $0.6 \%$ & 0.3 & 0.2 \\
\hline 10 & 1.1 & 4.43 & $0.9 \%$ & 0.5 & 0.3 \\
\hline 10 & 1.7 & 4.45 & $1.2 \%$ & 0.8 & 0.5 \\
\hline 10 & 2.2 & 4.46 & $1.5 \%$ & 1.0 & 0.6 \\
\hline 10 & 2.8 & 4.47 & $1.8 \%$ & 1.3 & 0.7 \\
\hline 10 & 3.3 & 4.49 & $2.2 \%$ & 1.5 & 0.8 \\
\hline 10 & 3.9 & 4.50 & $2.5 \%$ & 1.7 & 0.9 \\
\hline 10 & 4.4 & 4.51 & $2.8 \%$ & 1.9 & 0.9 \\
\hline 10 & 5 & 4.53 & $3.1 \%$ & 2.1 & 1.0 \\
\hline 10 & 5.6 & 4.54 & $3.4 \%$ & 2.2 & 1.0 \\
\hline
\end{tabular}




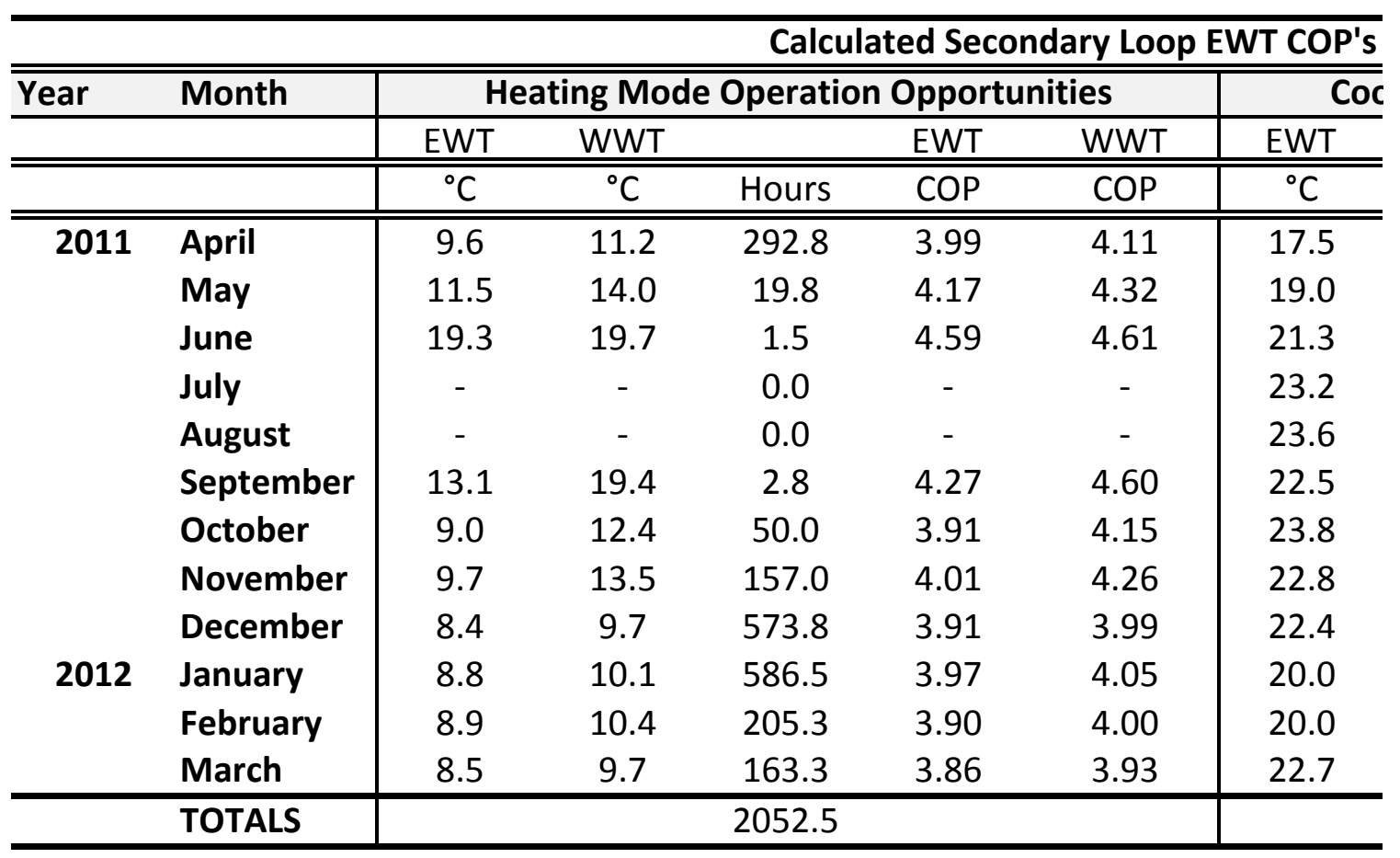




\begin{tabular}{|c|c|c|c|c|c|c|}
\hline \multirow{2}{*}{\multicolumn{4}{|c|}{$\begin{array}{l}\text { Current/Proposed } \\
\text { ling Mode Operation Opportunities }\end{array}$}} & \multicolumn{3}{|c|}{ Power/Energy Savings } \\
\hline & & & & \multicolumn{2}{|c|}{ Average Savings } & \multirow{2}{*}{$\frac{\text { Energy Savings }}{\text { Total }}$} \\
\hline WWT & & EWT & WWT & Heating & Cooling & \\
\hline${ }^{\circ} \mathrm{C}$ & Hours & $\mathrm{COP}$ & COP & $(\mathrm{kW})$ & $(\mathrm{kW})$ & (kWh) \\
\hline 13.6 & 252.0 & 5.64 & 6.23 & 0.3 & 1.4 & 441.7 \\
\hline 15.9 & 674.5 & 5.30 & 5.82 & 0.3 & 0.9 & 633.9 \\
\hline 18.7 & 640.0 & 4.94 & 5.33 & 0.0 & 0.9 & 586.2 \\
\hline 21.7 & 744.0 & 4.72 & 4.92 & - & 1.1 & 837.7 \\
\hline 22.1 & 632.5 & 4.68 & 4.89 & - & 0.8 & 530.3 \\
\hline 21.0 & 677.5 & 4.77 & 5.03 & 0.2 & 0.7 & 459.3 \\
\hline 18.9 & 534.8 & 4.62 & 5.24 & 0.3 & 1.3 & 694.4 \\
\hline 16.2 & 314.8 & 4.68 & 5.44 & 0.3 & 0.8 & 305.1 \\
\hline 16.2 & 47.3 & 4.62 & 5.46 & 0.3 & 0.7 & 182.1 \\
\hline 11.3 & 24.5 & 4.99 & 6.32 & 0.2 & 0.5 & 136.2 \\
\hline 12.7 & 141.5 & 5.09 & 6.32 & 0.1 & 1.0 & 154.0 \\
\hline \multirow[t]{2}{*}{15.0} & 378.0 & 4.78 & 5.81 & 0.1 & 1.7 & 656.8 \\
\hline & 5061.3 & & & & & 5,618 \\
\hline
\end{tabular}


Figures

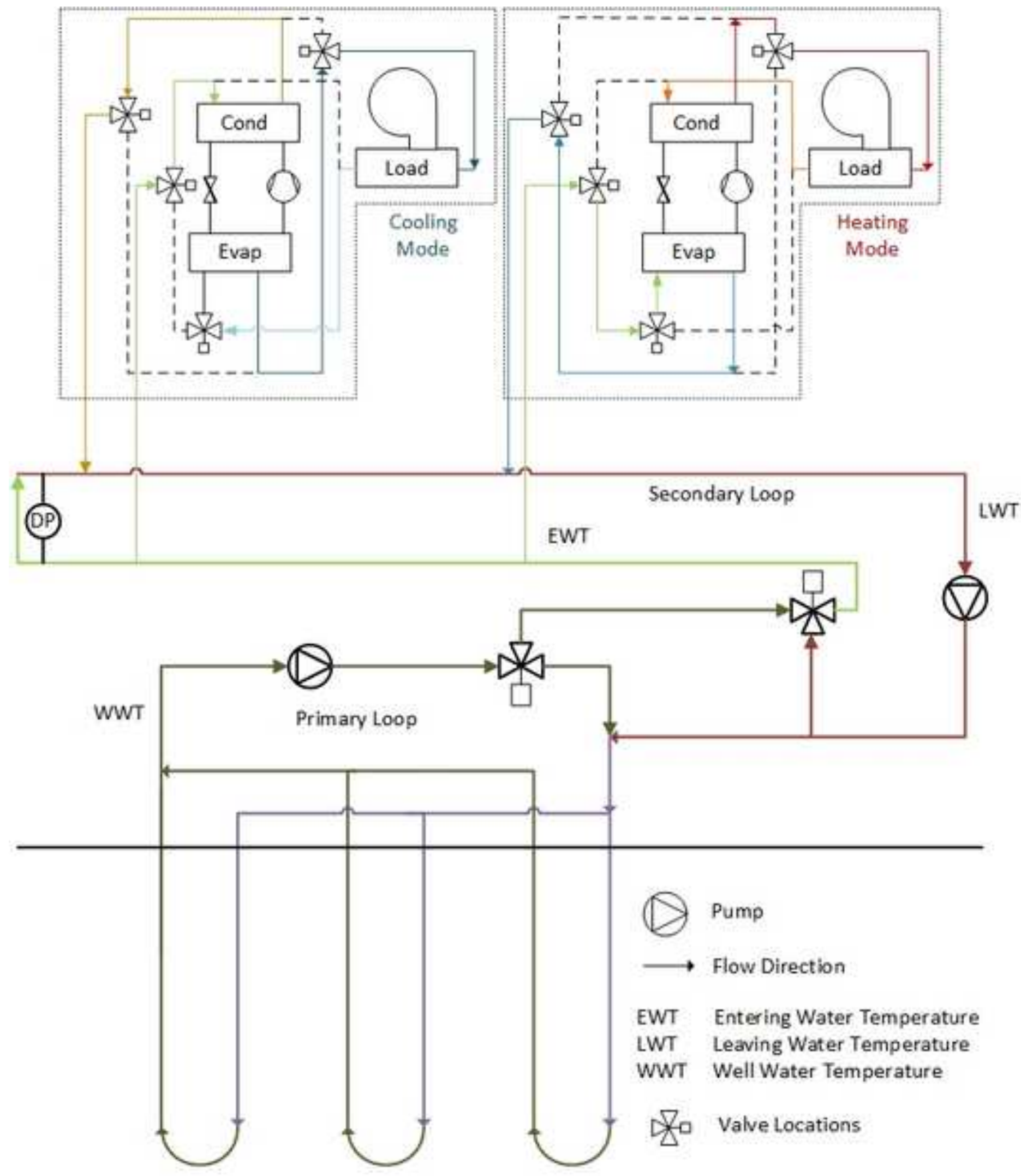




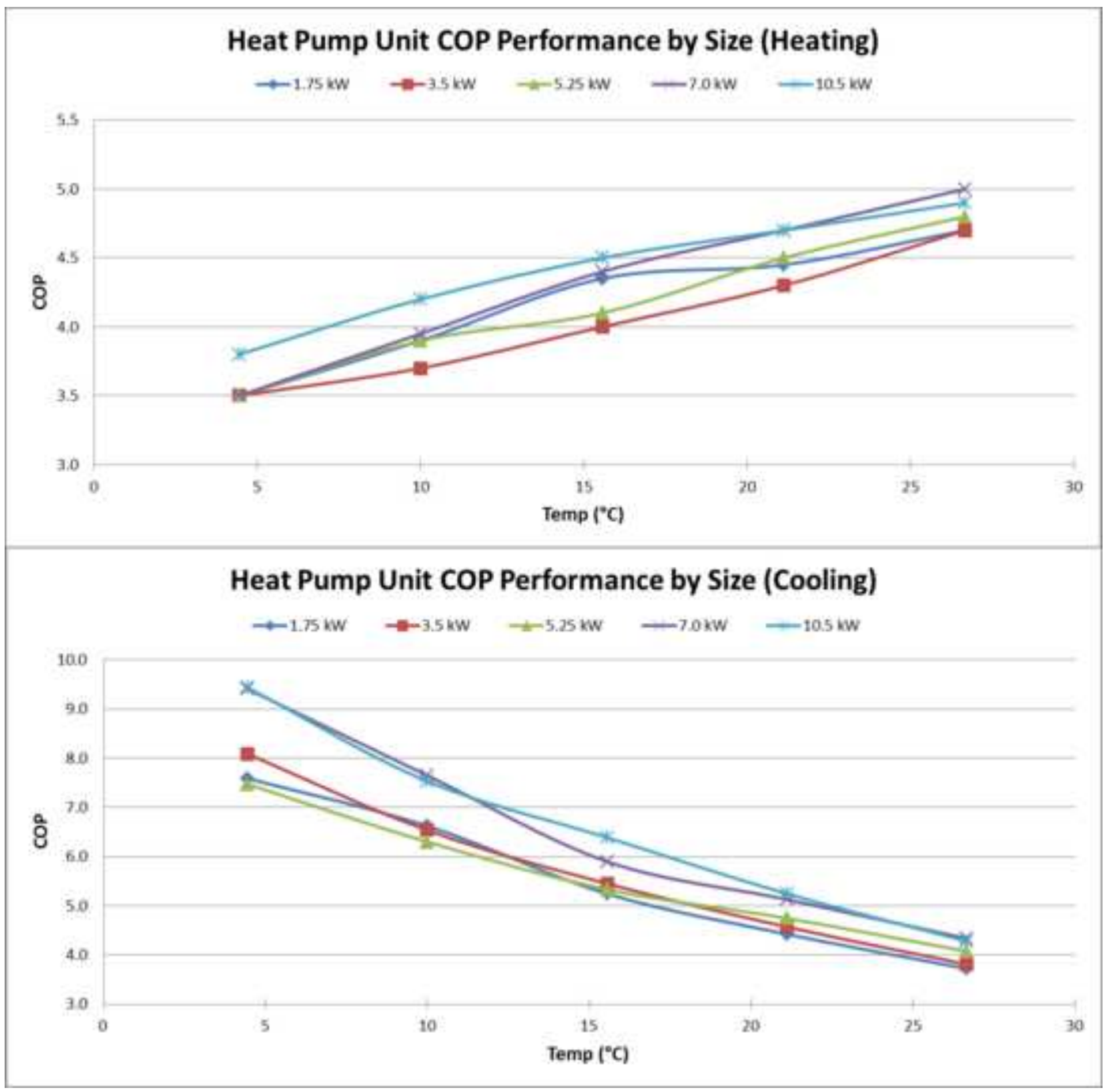


fig 3

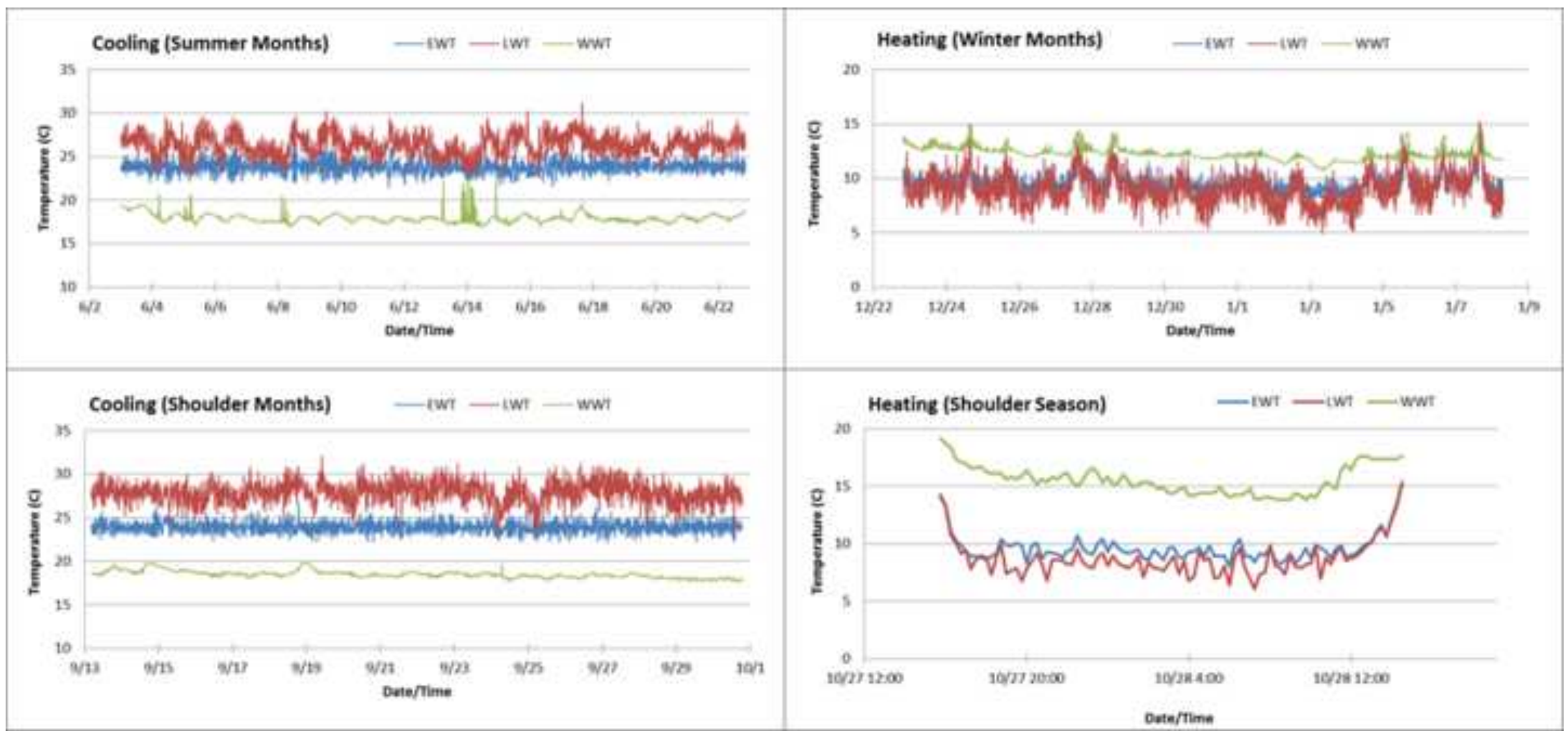




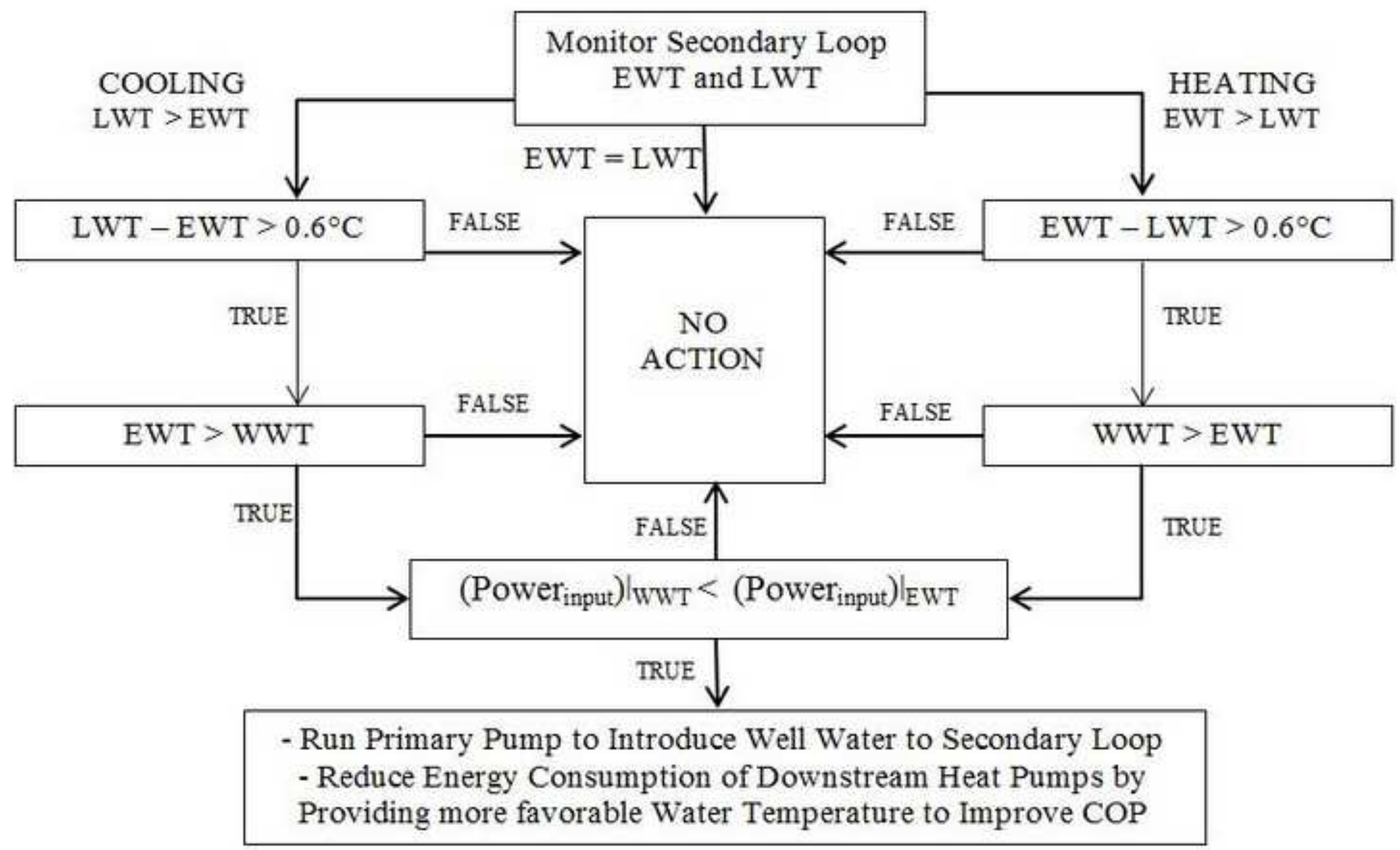




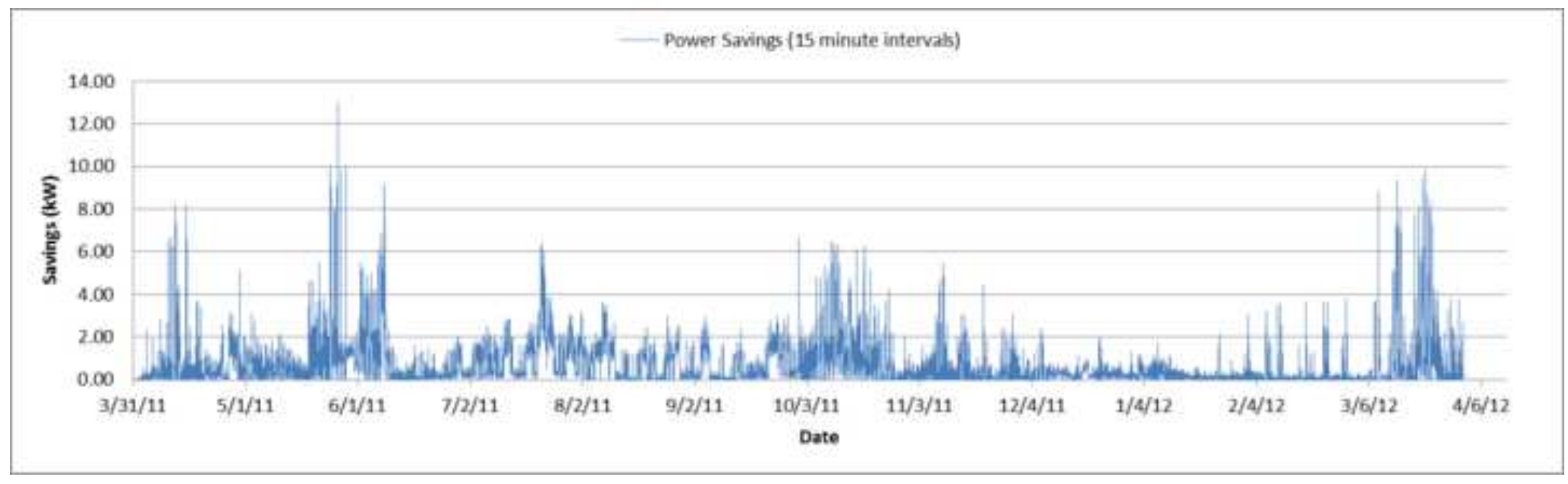




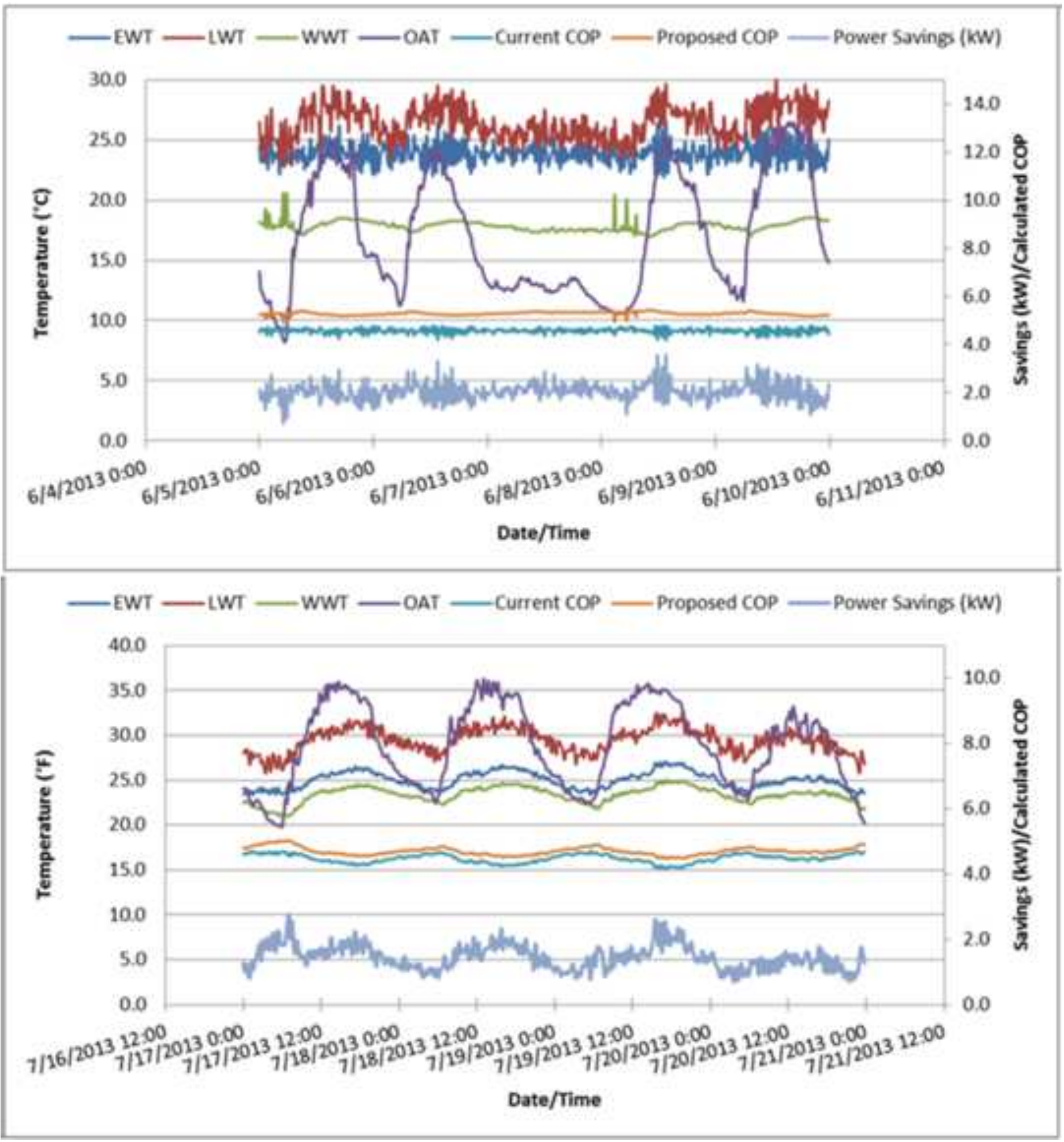


Fig. 1. Diagram of the primary-secondary pumping scheme as configured in the BAS. Arrows indicate the direction of water flow and the EWT/LWT/WWT bullets indicate where the BAS measures water temperature

Fig. 2. COP curves for various EWT for all heat pumps in heating and cooling modes of operation.

Fig. 3. Sample of opportunities that exist with increasing the COP through introducing the WWT to the secondary GSHPs loop for both heating and cooling modes: Notice heating shows the least amount of opportunity for this system.

Fig. 4. Flow chart to show logic of proposed algorithm which will introduce the primary loop water into the secondary loop to improve the COP of the system and reduce energy consumption

Fig. 5. Algorithm results using real time actual data collected from the BAS. Notice the most opportunities are found during the shoulder and summer months

Fig. 6. Analysis results for two periods of the year with the proposed control algorithm. The June period had milder weather with a reduced HVAC load where the July period experienced a heat wave with a high HVAC load 
